\title{
SYNTACTIC DISCONTINUITY IN A DYNAMIC MODEL OF EXPRESSION RULES ${ }^{1}$
}

\author{
JAVIER MARTÍN ARISTA \\ University of La Rioja
}

\begin{abstract}
This journal article addresses the question of the implementation of a dynamic model of expression rules in Functional Grammar (Dik 1997a, b) by considering sintactic discontinuity in Old English, a topic which has far-reaching methodological and theoretical implications and bears on the current debate in the $F G$ community, namely the top-down orientation of a discursive model of grammar. To begin with, this journal article provides a reflection on the role of syntax in FG and revises some aspects of previous approaches to expression rules that are relevant for the discussion of discontinuity. Discontinuous constituency, which is characterized in terms of three functional principles, is considered in the more general setting of the dynamic model of expression rules. The conclusion is reached that the functional features of any tree containing discontinuous constituents must specify the target, the degree of implementation and the degree of overlapping of discontinuous constituency. To round off, this journal article focuses on the implications of these conclusions for Functional Discourse Grammar by discussing parallel processing in the grammatical and the conceptual components.
\end{abstract}

\section{INTRODUCTION}

This paper addresses the question of the implementation of a dynamic model of expression rules in Functional Grammar, hereafter FG, by considering syntactic discontinuity in Old English. ${ }^{2}$

1. The research reported here has been funded through the project ANGI 2003/06. I should like to thank the two anonymous referees of Journal of English Studies for their useful suggestion and accurate remarks. The final version of this paper has greatly benefited from their revision.

2. For an account of several aspects of Old English syntax on functional principles, see Martin Arista (2001a, b). 
Bakker (2001: 49) makes the following provision for syntactic discontinuity in the dynamic model:

A second point that is not problematic for the dynamic model is the one demonstrated in example (15) ["that speared man kangaroo big"-JMA], more in general: any form of discontinuity in the expression of elements stemming from one underlying constituent. There does not seem to be any principled problem with expressing the respective elements of some underlying entity, say: a term, at different intervals during the expression process. The only condition is that they can be specified in an explicit manner, with the right set of operators, which is a technical rather than a linguistic matter.

What the following discussion underlines is that the question of syntactic discontinuity is not simply a technical matter. It has far-reaching methodological and theoretical implications. Moreover, it bears on the current debate in the FG community, namely the top-down orientation of a discursive model of grammar.

One of the most significant questions that syntactic discontinuity poses is the one of non-iconic syntax. Bakker (2001: 35) assumes iconicity between the underlying expression and the linguistic expression, which is not the case with discontinuous constituency. Even though Bakker does not rule out non-iconic syntax, this author considers trees with unrestricted daughter nodes flat. In this paper I hold that for a theory of constituency to be truly dynamic it is necessary that non-iconic syntax is also accounted for.

This paper is organized as follows. Section 2 provides a reflection on the role of syntax in FG and stresses the pending task of syntactic constituency. Section 3 reviews some aspects of previous approaches to expression rules that are relevant for the present discussion. Section 4 addresses the question of the definition of discontinuous constituency, which is characterized in terms of three functional principles. Section 5 deals with discontinuous constituency in the dynamic model of expression rules. The conclusion reached is that the functional features of any tree containing discontinuous constituents must specify the target, the degree of implementation and the degree of overlapping of discontinuous constituency. Section 6 focuses on the implications of these conclusions for Functional Discourse Grammar by discussing parallel processing in the grammatical and the conceptual components. To round off, some conclusions are drawn in Section 7.

\section{A BRIEF REFLECTION ON THE ROLE OF SYNTAX IN FUNCTIONAL GRAMMAR}

Functional Grammar (Dik 1997a, b) has been concerned with the functional explanation of universal phenomena of language for a quarter of a century and has 
contributed to the linguistic debate in an outstanding manner in areas like predication, transtivity and voice, operators, satellites, non-verbal predication and discursive functions, to mention just a few. The focus so far has been on semantics and pragmatics, not on syntactic structure. In the realm of syntax, FG has taken part in the discussion of clausal relations that has occupied syntacticians from several schools for the last thirty-five years, while this theory has postponed the engagement in syntactic structure to the moment when its functional credo could not be denied. Constituent order represents an exception in this respect. ${ }^{3}$ Unlike syntactic constituency, constituent order has been dealt with since relatively early in the development of the theory. After Dik's (1980: 23) seminal proposal on LIPOC (language-independent preferred order of constituents), a number of functional principles governing the ordering of clausal constituents followed in Dik (1997a). Such principles are ingenious and elegant when the main concern is with clausal relations like the pragmatic functions Topic and Focus. If the main aim is to provide a syntactic description, however, Dik's principles of constituent ordering fall short because the motivation of syntax might be mistaken for syntax itself: saying that constituents with special pragmatic functions tend to occupy initial or final positions does not describe the syntactic constituency of the clause under analysis; neither does it explain such constituency. A similar criticism could be applied to expression rules as a whole. In my opinion, Dik's (1997a) morphology is oversimplified because the principles of morpheme ordering are identified with the principles of word and phrase ordering, which neglects the fundamental fact that morpheme ordering has phonological consequences that do not play a role in the ordering of words and phrases. ${ }^{4}$ In a similar vein, phonology is oriented towards the assignment of pragmatic functions. Paradoxically, pragmatic function assignment is, to a large extent, reduced to relative order and suprasegmentals, while little attention has been paid to other resources like special morphology, special words and duplication. All in all, however, the discussion of focalizing constructions in Dik (1997b) evidences a significant move in this respect.

\section{PREVIOUS APPROACHES TO EXPRESSION RULES}

I revise previous approaches to expression rules very briefly. The emphasis will be on constituent order, not only because it has been the main concern of FG in previous research, but also because this paper is about constituency problems.

3. See Van Valin (1990) and Butler (2003a, b).

4. But see Bakker and Siewierska (2002) on the diachrony of adpositions and the development of case markers out of prepositions within the dynamic model of expression rules. 
Dik (1980: 125) defines functional patterns as sequences of designated positions to which the constituents of predications are brought by placement rules, given their functional and structural properties within the predication. (1) is a functional pattern, in which $\mathrm{S}, \mathrm{V}$ and $\mathrm{O}$ represent pattern positions and $\mathrm{P} 1 \mathrm{a}$ special position.

(1) Theme, P1 (V) S (V) O (V), Tail

The simplicity of (1) is due to the fact that Dik's aim was typological validity. Although Connolly (1991: 54) considers Dik's functional patterns useful for typological work, this author opts for a more detailed approach for intralinguistic purposes that makes use of a full inventory of syntactic categories and functions. Connolly (1991: 51) replaces functional patterns with syntactic templates like (2):

(2) P1 N1 N2 N3 N4

In Connolly's (1991) proposal, functional patterns are derived from syntactic templates, which enjoy a primitive character. Syntactic templates do not draw functional distinctions such as Subject (S) vs. Verb (V). Instead, syntactic templates distinguish pattern positions such as N1 from special positions such as P1. Placement rules relate every function (Topic, Focus, Subject, Indirect Object, Direct Object, Complement and Predicator) to all five positions (the special position P1 and the four pattern positions). ${ }^{5}$

Connolly (1991) represents the Aristotelian intermediate position between function and structure: while concerned with the assignment of pragmatic funcions and communicative distinctions between unmarked and marked realizations, Connolly proposes a structural-functional description clearly rooted in the AngloSaxon grammatical tradition represented by Quirk et al (1991). ${ }^{6}$

Bakker (2001) makes a bold contribution to this discussion: by means of one of the favourite metaphors of linguists of the last two centuries, namely the tree metaphor, Bakker has reintroduced the topic of structure, that is, trees, nodes and branches, into the functional agenda. Bakker (2001), like Connolly (1991), keeps the orthodox distinction between underlying representations, which contain functional

5. The organizing principle is vacancy: if the leftmost position is empty, the consitutent is inserted into it; otherwise, it is aligned in the following position to the left (Connolly uses the term pushdown). The variable $\mathrm{T}$ determines the number of pattern positions in the template of a language. The condition if vacant, which allows for the insertion of a constituent into a position, prevents duplications and gaps. For more information, see Connolly (1991).

6. By means of IFF -if and only if- rules, Connolly (1991) assigns marked and unmarked positions to phrasal and clausal elements. Connolly (1991: 69) considers discontinuous postmodification marked with respect to continuous modification. 
and lexical information, and expression rules, which guarantee formal features of form, order and prosody. Bakker insists on the interdependence of form and function by stating that templates constitute structures in which the relevant functional and lexical information is directed towards the right place. Since the order of expression is from left to right, the appropriate template is always selected, in such a way that the underlying expression is assigned the right slot, without gaps or duplications. According to Bakker (2001), a dynamic expression rule component requires five principles: the top-down principle (constituent structures are developed top-down), the left-to-right principle (constituents are developed from left to right), the depth-first principle (leftmost constituents are completely expanded before rigthmost constituents are considered), the inheritance principle (operators are available from a given node to the top of the node) and the perlocation principle (operators may move up to higher nodes).

\section{DISCONTINUOUS CONSTITUENCY: FUNCTIONAL AND FORMAL FEATURES}

At this point of the discussion, it is not out of place to make two remarks on Old English constituent order. Firstly, Old English allowed orderings of constituents that are no longer grammatical in Present-Day English, such as verbinitial statements like (3):

\section{(3)}

Woes todoeled in foreweardum Danieles dagum

was divided in the following of St. Daniel day

in tua biscira West Seaxna lond

into two bishoprics the West Saxon land

"The West Saxon land was divided into two bishoprics on the following day of St. Daniel” (Anglo-Saxon Chronicle, Anno 959)

And, secondly, some of these constituent orderings might be explained as intermediate stages in the evolution from SOV to SVO basic order (Dik 1997a: 413). An example in point is the following. Notice the clause-final position of the past participle:

\section{(4)}

\section{Seo is Legaceaster gehaten}

it is Chester called

"It is called Chester" (Anglo-Saxon Chronicle, Anno 893) 
This paper, however, does not concentrate on examples in which discontinuity might be reduced to V2 or VX rules. On the contrary, most of the examples that follow are difficult to come to terms with in a strictly positional approach.

Discontinuous constituency, or syntactic discontinuity, is defined in this paper as a violation of, at least, the functional principle that follows (Dik 1997a: 402):

The Principle of Domain Integrity

Constituents prefer to remain within their proper domain; constituents prefer not to be interrupted by constituents from other domains

In some instances, discontinuous constituency also conspires against the following functional principle (Rijkhoff 1986:100):

The Principle of Head Proximity

The head of a domain prefers to be contiguous to the head of its superordinate domain

An example in point is:

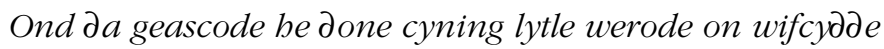

And then discovered he the king with a little troop with a mistress

on Merantune, ond bine doer berad

at Merton, and him there rode

ond done burh utan beeode ar bine da men

and the town surrendered before him the men

onfunden $\partial$ e mid dam kyninge warun

discovered that with the king were

"And then he discovered he that the king was with a little troop with a mistress at Merton, and he rode after him and the town surrendered before the men who were with the king discovered him." (Anglo-Saxon Chronicle, Anno 755).

In (5) the integrity of the domain of the term phrase $\partial a$ men $\partial e$ mid $\partial a m$ kyninge warun 'the men who were with the king' is broken by the verbal predicate onfunden 'found', which constitutes a violation of the Principle of Domain Integrity. On the other hand, the head of the term phrase men 'men' and the head of its superordinate domain, the verbal predicate onfunden 'found', are 
adjacent, which is consistent with the Principle of Head Proximity. The following example illustrates the simultaneous violation of both functional principles:

(6)

da ridon hie dider, ond his aldormon Osric, ond Wiferd his degn, then rode they there, and his aldormon Osric, and Wiferd his thane, ond $\partial$ a men $\partial e$ be beaftan bim laefde oer,

and the men that he behind him left before

ond done aedeling on dare byrig metton daer se cynning ofslaegen laeg and the prince in the town met where the king dead lay

"Then they rode there, and his ealdorman Osric, and his thane Wigfrith, and the men that he had left behind him, and found the prince in the town where the king lay dead." (Anglo-Saxon Chronicle, Anno 755)

In example (6) the linguistic expression $\partial$ a ridon hie dider, ond his aldormon Osric, then they rode there, and his aldormon Osric' does not follow the Principle of Domain Integrity, since the Subject of ridon 'ride', is multiple and appears to the left and to the right of the verbal predicate. Moreover, the head of the term phrase, bie ond his aldormon Osric they and his aldormon Osric', is partly separated from the head of the superordinate domain by additional material ( $\partial$ ither 'there'). In the same example, there is a violation of the Principle of Domain Integrity in the nonadjacency of the term head byrig the town' and its verbal restrictor, doer se cynning ofsloegen loeg where the king lay dead'. Additionally, the linguistic expression done axdeling on dare byrig metton '[they] met the prince in the town' does not comply with the Principle of Head Proximity, given that the term head is non-adjacent with the head of its superordinate domain, the verbal predicate.

Another general principle is relevant for a functional definition of discontinuous constituency, namely the Principle of Iconic Ordering (Dik 1997a: 399):

\section{The PRINCIPLE OF ICONIC ORDERING}

Constituents conform to GP1 [The Principle of Iconic Ordering-JMA] when their ordering in one way or another iconically reflects the semantic content of the expression in which they occur.

This general principle may be specified for the purposes of discontinuous constituency as follows. Constituents represent expansions from hierarchical

7. Notice that no position-filler is left in canonical position by the displaced subconstituent, either in Old English or in Present-Day English. See Givón (1993 vol II: 143) and McCawley (1998: 104). 
semantic structures called underlying predications: argument positions of verbal predicates plus satellite positions of predications, propositions and clauses receive expression. This expression can be either iconic or non-iconic: iconically, what belongs together semantically remains together syntactically; iconically, too, units receive single expression. The first member of the following pairs represents the iconic version, the second member of the pair being non-iconic:

(7)

a. The old argument that war was the only option was trotted out.

The old argument was trotted out that war was the only option.

b. Fred retired and Fred wrote a novel.

Fred retired and wrote a novel.

c. The bike bumped into the van.

It was the bike that bumped into the van.

If the view that iconic expression requires adjacency and single expression is adopted, (7.a) does not meet the condition of adcencency of the nominal head and the verbal restrictor; (7.b) does not meet the condition that all semantic participants receive full expression; and (7.c) does not meet the condition that semantic participants are expressed once.

Structurally, discontinuous constituency implies non-adjacency. This is not enough, though. Although the geometry of discontinuous constituency is its most obvious characteristic, there are other characteristics that cannot be overlooked, including at least the notions of hierarchy and dependence. The transformational tradition has regarded constituency as the result of two dimensions: the vertical and the horizontal dimension. In the vertical dimension (the y axis) immediately smaller constituents depend on immediately larger constituents, whereas in the horizontal dimension (the $\mathrm{x}$ axis) previous constituents precede subsequent constituents. Such a theory of constituency neglects a fundamenal factor: hierarchy. At the same time, such a theory of constituency mistakes semantic dependence for syntactic implementation. Dependence is a semantic property: predicates take arguments, which depend semantically on predicates; arguments fill semantic slots of predicates, but the syntax of the relationship of dependence is a derived question, not a primitive one. Hierarchy, on the other hand, is a syntactic property. Hierarchy implies that elements are compulsory or optional. In other words, hierarchy is the property that distinguishes lower from higher levels of implementation: a given constituent may consist of a head or of a head plus several dependents. Even though the notion of head has generally not found much favour in FG, the dynamic model of expression rules has reintroduced it. Moreover, the discussion of 
discontinuous contituency reinforces this notion, since the head is the element that tends to occupy the canonical position in the order of the clause while the dependents (term operators or restrictors) tend to be displaced to the right. This is the case with the following example:

Ond hiera de aedeling gebwelcum feoh ond feorh gebead, and of them the prince each money and life offered, ond hiera noenig bit gedicgean nolde

and of them none it accept would

"And the prince offered each of them money and security, but none of them would accept them" (Anglo-Saxon Chronicle, Anno 755)

The head of the term phrase is the element that typically occupies the canonical position of the term phrase in discontinuous constituency. The linguistic expressions biera de axdeling gehwelcum feoh ond feorh gebead of them the prince each money and life offered' and biera noenig bit gedicgean nolde 'of them none it accept would' are parallel, both following the pattern SOV. In the former, the Object-Recipient is discontinuous and consists of the head gebwelcum 'each' in canonical position, following the Subject; and hiera 'of them' in non-canonical position preceding the Subject. In the latter linguistic expression both head and non-head take up Subject position.

It is also the case that multiple heads which semantically belong together typically result in discontinuous constituency. This is illustrated by the following example:

(9)

daer weard Sidroc eorl ofsloegen se alda,

there was Sidroc earl slain the old,

ond Sidroc eorl se gioncga ond Osbearn eorl,

and Sidroc earl the young and Osbearn earl

ond Frona eorl, ond Hareld eorld

and Fræna earl, and Harold earl

"There earl Sidroc the Old was slain, and Sidroc the Young, and earl Osbearn and earl Fræna and earl Harold" (Anglo-Saxon Chronicle, Anno 871)

The long multiple head in this example is divided into two parts by the verbal predicate ofslaegen 'slain'. Considering the linguistic expression doer weard Sidroc eorl ofslaegen se alda, 'there earl Sidroc was slain the old', Sidroc se alda is dicontinuous, like the verbal predicate weard ofslagen 'was slain'. The head Sidroc 
eorl 'earl Sidroc' remains in canonical position. Pragmatically speaking, there is a displacement of information towards the end of the expression. As I have already remarked, the pragmatic motivation cannot be mistaken for the syntactic description, which involves syntactic discontinuity.

Along with the domain of the term phrase, the verbal predicate is the other constituent that typically undergoes discontinuity in Old English. The nature of such discontinuity, however, is substantially different: whereas the head typically keeps the canonical position in discontinuous term phrases in such a way that a restrictor or an operator is displaced, the copula or the grammatical operator tends to take up the canonical position if the verbal predicate is discontinuous. Relevant examples of copula and operators, respectively, are:

(10)

a. Ja waron bie mid metelieste gewoegde

then were they by want of food reduced

"Then they were reduced by want of food" (Anglo-Saxon Chronicle, Anno 893)

b. Ac hi hæfdon da heora stemn gesetenne

but they had then their service ended

on biora mete genotudne

and they food used up

"But they had already ended their service and used up their food" (AngloSaxon Chronicle, Anno 894)

In (10.a) the copula waron 'were' occupies the canonical position, the verbal predicate gewoedge 'reduced' being clause-final; similarly, in the first clause in (10.b) the grammatical operator bafdon 'had' appears in canonical position while the verbal predicate is clause-final. In the second clause in (10.b) the operator is not expressed because it is shared with the first clause.

\section{DISCONTINUOUS CONSTITUENCY IN THE DYNAMIC MODEL OF EXPRESSION RULES}

At the pre-theoretical level, the implementation of a dynamic model of expression rules requires a basic choice between language constructions and language expressions. By construction I mean the Bloomfieldian concept of construction, which involves a recurrent association of form and meaning. The concept of construction, therefore, encapsulates a purely theoretical notion that interacts with the concept of linguistic expression in such a way that a given 
expression may partake in more than one construction. If the methodological choice, as in Dik (1986) and Bakker (2001), is to describe and explain actual language, the concern must be with expressions rather than with constructions. The study of linguistic expressions allows for an overall approach to the phenomena of language whereas the focus on restricted areas of the grammar may result in partial solutions of linguistic problems. Consequently, what I suggest is to opt for linguistic expressions.

The next pre-theoretical step for implementing a dynamic model of expression rules is to classify linguistic expressions. For the purposes of expression rules, linguistic expressions can be divided into structurally-oriented expressions and functionally-oriented expressions. This is tantamount to saying that linguistic expressions are profiled in two different ways: structure-profiled and functionprofiled. Most expressions are structurally-oriented. They keep a high structural profile, whereas their functional profile is low. Some expressions are functionallyoriented. Conversely, functionally-oriented expressions keep a low structural profile and show a high functional profile. Figure 1 illustrates this classification:

\begin{tabular}{|l|c|c|}
\hline & $\begin{array}{l}\text { STRUCTURALLY-ORIENTED } \\
\text { LINGUISTIC EXPRESSIONS }\end{array}$ & $\begin{array}{l}\text { FUNCTIONALLY-ORIENTED } \\
\text { LINGUISTIC EXPRESSIONS }\end{array}$ \\
\hline $\begin{array}{l}\text { STRUCTURAL } \\
\text { PROFILE }\end{array}$ & high & $\mathbf{l o w}$ \\
\hline $\begin{array}{l}\text { FUNCTIONAL } \\
\text { PROFILE }\end{array}$ & low & $\mathbf{h i g h}$ \\
\hline
\end{tabular}

Figure 1. Structural and functional profile of linguistic expressions.

This is not to say that certain expressions have structure only whereas others enjoy both structure and function. One of the cornerstones of the functional tradition is precisely to acknowledge the functional value of linguistic units at clause level, below clause level and above clause level. What I mean is that functionallyoriented expressions display a higher functional profile because they opt for expresiveness at the expense of straight structure, thus calling for a higher processing effort than expressions with a straight structure but less expressive power. Linguistic expressions that display syntactic discontinuity as it is defined in section 4 constitute functionally-oriented expressions, while expressions involving continuous syntax qualify as structurally-oriented expressions. 
Shifting to purely theoretical questions, the tree of a functionally-oriented expression is fully specified. Typically, its functional information should include, at least, three items: the target of the expression, its degree of implementation, and the degree of overlapping of intervening constructions. Let us discuss them in turn. ${ }^{8}$

Considering the target of the linguistic expression, it is necessary for the functional information to identify the (sub)constituent that undergoes discontinuity. Expression targets can be semantically, syntactically or pragmatically constrained. The zero relative construction in Old English, for instance, is restricted to certain verbs of state (Visser 1963-73: 11; Mitchell 1985: 186). This is a semantic restriction. Syntactic restrictions include zero anaphora in coordination, to give just one example.? Since I assume non-synonymy between continuous and discontinuous constituency, discontinuity must stem from pragmatic considerations of communicative co-operation between speaker and hearer. In other words, the target of the linguistic expression is chosen in a top-down fashion. ${ }^{10}$ Let us consider example (11):

\section{(11)}

Ac hie simle feohtende wæran oð hie alle lægon

but all continuously fighting were until they all lay dead

butan anum Bryttiscum gisle, ond se swide gewundad woes

but one British hostage, and he severely wounded was

"But they kept on fighting until all lay dead, except one British hostage, and he was severely wounded" (Anglo-Saxon Chronicle, Anno 755)

In the preceding example, the target of the expression is the Subject of the verbal predicate laegon 'lay'. The discontinuity between bie alle 'they all' and butan anum Bryttiscum gisle 'except one British hostage' is motivated not only by the afterthought but also by the coordinative expression ond se swide gewundad woes 'and he severely wounded was', in which se 'this' is co-referential with gisle 'hostage' in the afterthought.

8. It remains a task for future research to decide if the tree of structurally-oriented linguistic expressions might be simplified by means of default choices.

9. Throughout this paper I hold the view that there is not conclusive evidence for stating that Old English is a language with a generalized V2/V-final order, but see Pintzuk (1999) and Fischer et al. (2000). It logically follows that there is no syntactic restriction on the target and degree of implementation of verbal predicate discontinuity.

10. Note that the target of the expression is not identifiable with the pivot or the controller of the construction in the sense of Van Valin and LaPolla (1997). Pivots and controllers typically coincide with the noun phrase in which the complexity of the construction originates and, consequently, the functional relations of the clause can be explained with reference to the privileged syntactic arguments in the role of pivot or controller of the construction. 
With reference to the degree of implementation of the linguistic expression, syntactic discontinuity may display different degrees. Such degrees should be accounted for by the functional information of the tree. All of them are quantitative. The degree of discontinuity of a linguistic expression can be measured by means of the number of constituents that break into the discontinuous constituent. The degree of implementation of the linguistic expression operates basically in a topdown direction. In the following examples, one constituent breaks into the verbal predicate in (12.a), whereas up to three constituents separate bafde 'had' and tonumen 'divided' in (12.b). Consequently, the degree of implementation of the linguistic expression is higher in (12.b) than in (12.a):

a. Ja hergas woron $\partial$ a gegaderode begen to Sceobyrig on Eastseaxum the hosts were then gathered at Shoebury in Essex

"Then the hosts were concentrated at Shoebury in Essex" (Anglo-Saxon Chronicle, Anno 893)

b. Hafde se cyning bis fierd on tu tonumen

had the king his army in two divided

"The king had divided his army into two sections" (Anglo-Saxon Chronicle, Anno 894)

As regards the degree of overlapping of the linguistic expression, structurallyoriented and functionally-oriented linguistic expressions are classified functionally, on the basis of the types of predicates considered by the theory: verbal, nominal, adjectival and adpositional (following Mackenzie 2001). This functional classification allows for the treatment of construction overlapping. I explain this by means of the following example:

(13)

da weard geond eall Englaland swylc tacen on

there was around all England such a token on

beofenum gesewen swilce nan man oer ne geseah

heaven seen as no man before not saw

"There was all over England such a token seen as no man ever saw before" (Anglo-Saxon Chronicle, Anno 1066)

In the previous example, two instances of discontinuous constiuency coexist: there is non-adjacency in the verbal predicate weard gesewen 'was seen' and in the term phrase swylc tacen swilce nan man aer ne geseab 'such a token as no man before not saw'. Discontinuity is not likely to overlap with itself. Much more 
frequently, it overlaps with constructions like gapping, as the following example shows. In example (10.b), which I repeat below as (14) for convenience, the discontinuity of the verbal predicate hoefdon gesetenne 'had ended' overlaps with the omission of the operator of the verbal predicate genotudne 'used up'. ${ }^{11}$

Ac hi hæfdon $\partial \mathrm{a}$ heora stemn gesetenne

But they had then their service ended

on biora mete genotudne

and their food used up

"But they had already ended their service and used up their food" (AngloSaxon Chronicle, Anno 894)

As I have already pointed out, a significant characteristic of discontinuous constituency is its non-synonymy with continuous constituency. The choice between the continuous and the discontinuous term phrase in linguistic expressions like (13) is not random: it has a functional import or, more generally, must be externally motivated. Throughout this paper the central idea is that discontinuous constituency originates in choices at the highest linguistic level, the discursive level. From the top to the bottom, upper choices fuel lower choices and constituents remain together or are split in cascade. The only exception to the non-synonymy approach to discontinuous constituency might be found in diachronic processes in which a language has favoured one structure over other structures which are in competition with it. In the following example the verbal predicate is continuous in (15.a) and discontinuous in (15.b)

(15)

a. Her Herebribt aldormon waes ofslaegen from boednum monnum

Here Herebriht earl was slain by heathen men

"This year Herebriht was slain by the heathen" (Anglo-Saxon Chronicle, Anno 838)

b. daer waeron eac odre VII brodru be naman gecigde

There were also other seven brothers by name called

"There were also other seven brothers called by name" (Anglo-Saxon Chronicle, Anno 867)

11. The degree of overlapping that a certain linguistic expression undergoes might be determined both in a top-down and in a bottom up fashion, but this constitutes another task for future research. 
The intermediate or final position of the past participle forms ofslagen 'slain' and gecidge 'called' respectively represent what Kroch (1989) calls grammars in competition: there is a moment in the evolution from OV to VO order in which the speaker can opt for inserting the past participle post-verbally or finally. ${ }^{12}$ Assuming that the assignment of pragmatic functions in (15.a) and (15.b) is the same, diachrony-competing structures might be the only exception to the principle of non-synonymy as applied to syntactic discontinuity.

Summarizing, discontinuous expressions have been classified as functionallyoriented and, as such, they have been characterized as requiring functional specifications of target, degree of implementation and degree of overlapping.

Bakker's (2001) principles and nodes provide the information relevant for hierarchy and dependency relations: relative position (the left-to-right principle), degree of implementation (the depth-first principle), and morphosyntactic cohesion (inheritance and perlocation, that is, operator scope). Constituents are generated in a top-down fashion. The development of constituents takes place in the unmarked order and is governed by the depth-first principle (leftmost slots are completely expanded before the expansion of rightmost slots begins). Inheritance and perlocation features guarantee that operators are attached to the selected constituent and that their scope reaches the top node of the constituent.

The dynamic model of expression rules does not allow for empty nodes. All of them require instantiation. Instantiation follows the linear principle of left-to right and the top-down principle of depth-first. The simultaneous operation of both principles determines that the leftmost element must reach terminal form before the rightmost element is considered. In order to preserve these two principles, it is necessary to consider the notion of parallel processing. In this line, Bakker (2001: 49) admits:

Psychological models of speech suggest that a purely left-to-right model is too simplistic. There is ample evidence, not in the least from the analysis of speech errors, that language processing in the speaker takes place in a parallel fashion: roughly, while a first part of the sentence in being expressed, a second part may still be in the process of being semantically conceptualized, while a third part is still at a prelinguistic stage (cf. Levelt 1989).

In the remainder of this paper I explore parallel processing as applied not to different parts of a sentence, but to a single constituent of a clause. Parallel 
processing, in this approach, consists of the simultaneous instantation of a single constituent in two slots. Let us apply this proposal to the following example:

(16)

Hie wurdon $\partial \mathrm{a}$ gebrohte to $\partial x \mathrm{~m}$ biscope

they were then brought to the bishop

"Then they were taken to the bishop" (Anglo-Saxon Chronicle, Anno 1014)

In (16) the copula wurdon 'were' and the verbal predicate gebrobte 'brought' are not adjacent to each other, thus involving discontinuous constituency.

A sketchy representation of the constituent tree of (16) introducing parallel processing is given in (17). Vertical arrows represent processing: top-down generation, left to right development, depth first and operator scope. A single vertical arrow represents linear processing, whereas two vertical arrows mean parallel processing. ${ }^{13}$

\section{1: SENTENCE \\ 2: $\mathrm{P} 1$ \\ 3: PRONOUN}

4: VFIN

6: VNFIN

7: DIRECTION: TERM

Hie wurdon da gebrohte to $\partial æ m$ biscope

In (18) barriers (Bakker 2001) are inserted. Downward barriers make the segment inserted into the canonical position (the copula) inaccessible to lower nodes and upward barriers that make the displaced element (the verbal predicate) inaccessible to higher nodes. The horizontal arrow represents barrier insertion:

13. Abbreviations, after Bakker (2001), are used with the following meaning: P1 (clause-initial position), VFIN (finite form of the verb), VNFIN (non-finite form of the verb) and FcnFtrs (functional features). 
(18)

\section{1: SENTENCE}

2: $\mathrm{P} 1$

3: PRONOUN

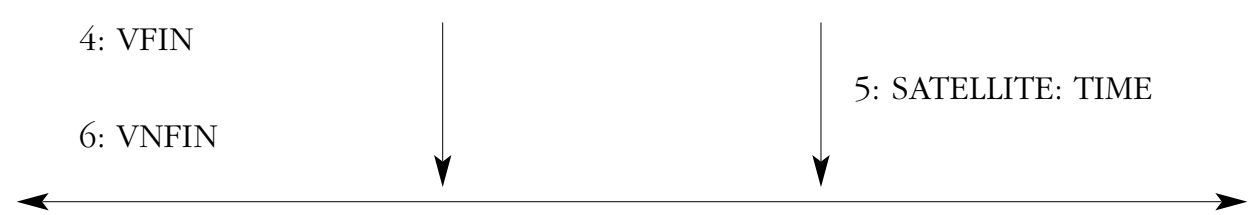

\section{7: DIRECTION: TERM}

Hie wurdon $\partial \mathrm{a}$ gebrohte to $\partial æ m$ biscope

I have already remarked that the tree of a expression with a high functional profile is fully specified. Its functional features should include, at least, three items: the target of the expression, its degree of implementation, and the degree of overlapping of intervening constructions. (19) contains the functional features corresponding to target, degree of implementation and degree of overlapping of node 4 :

(19) FncFtrs:

TARGET: V, N4-N6

IMPLEMENTATION: 1 , N5

OVERLAPPING: no

Hie wurdon $\partial \mathrm{a}$ gebrohte to $\partial æ m$ biscope

(19) is interpreted as follows: the target of discontinuity is the verbal predicate, whose finite part is implemented in node 4 and whose non-finite part is implemented in node 6. The implemetation tells us that one constituent, represented by node 5 , breaks into the verbal predicate. The overlapping stipulates that there is a single instance of discontinuity and that the rest of the expression is not functionally-oriented. Although functionally we have adverbial insertion (the Time satellite $\partial a$ 'then') with the subsequent discontinuity between the copula and the verbal predicate, the notion of degree of discontinuity is cognitively relevant, since as regards short term memory matters are different. I go back to this question in section 6 . 


\section{IMPLICATIONS FOR FUNCTIONAL DISCOURSE GRAMMAR}

Hengeveld (2004 a, b) has put forward a radically new version of Functional Grammar called Functional Discourse Grammar (FDG) which is organized topdown, that is, a framework that proceeds from the speaker's intention to the linguistic articulation. From the perspective of generation, FDG consists of three components, the grammatical, the acoustic and the conceptual component. The grammatical component describes the interpersonal, representational and formal characteristics of linguistic expressions. The acoustic component provides audible form to the output of the grammar. The conceptual component is extralinguistic but may trigger certain grammatical features. From the parsing perspective, FDG includes the addressee into the model, thus considering a fourth component called the contextual component that is shared by the speaker and the addressee. The previous discussion of discontinous constituency in Old English may shed some light on the interaction between the conceptual and the contextual component. The main argument is that the conceptual component makes extralinguistic choices of processing effort whereas the contextual component provide (more) structurallyoriented or (more) functionally oriented profiles. Both componens operate simulatenously in such a way that the processing choice and the relevant profile trigger certain grammatical features, including syntactic discontinuity.

The speaker's intention is to modify the world in a certain way by using a linguistic expression (Dik 1997b: 410). In order to associate form and meaning, the speaker plans ahead the linguistic expression, which may be mainly oriented towads form or towards function, depending on whether its functional profile is low or high, respectively. Formally-oriented expressions are default expressions that require less planning than functionally-oriented constructions. Functionallyoriented expressions have, by definition, a structurally-oriented counterpart and display higher structural complexities, thus requiring more processing effort and, typically, parallel processing.

a. I hate bananas/I hate them, bananas

b. I like bananas/It is bananas that I like

c. I like bananas/What I like is bananas

Extraposition, clefting and pseudo-clefting, which involve constituent duplication, require a more costly planning strategy, but they are potentially more effective for communicative purposes. Topicalization is also more costly in terms of planning strategy, even though it does not entail constituent duplication: 


\section{(21) I like bananas/Bananas I like}

From the perspective of the hearer, parallel processing is also more demanding if one takes into account the short-term memory effort that is required.

In the grammatical component, linguistic expressions that have been planned with a functionally-oriented strategy must meet the requirement of having a structurally-oriented counterpart. Moreover, the test for the orientation to function is provided by the acoustic component: functionally-oriented expressions take at least as much articulation time as their structural counterparts. Notice that functionallyoriented expressions do not originate in function assignment: voice alternations resulting from object function assignment do not give rise to functionally-oriented expressions. Neither do second argument alternations that stem from object assignment allow for a choice between structurally and formally-oriented expressions.

Parallel processing follows the natural principle of left-to-right ordering. It involves the simultaneous instantation of a single constituent in two slots, in such a way that a subconstituent is non-adjacent to the constituent to the left. Parallel processing is cognitively plausible, since it is the semantic and syntactic dependent that non-adjacently follows the head, not the other way around. More importantly, parallel processing is not incompatible with the depth-first principle. On the contrary, it reinforces the notion of constituent and draws a clear distinction between the slots that constituents and subconstituents occupy and the nodes that precede such slots throughout the derivation.

\section{CONCLUSION: THE PRINCIPLE OF LINEAR PROCESSING}

In the preceding sections I have argued that, in order to provide an account of Old English syntactic discontinuity by means of a model of expression rules that is ultimately compatible with the overall organization of FDG, it is necessary to distinguish a processing effort choice from a profile choice. The processing effort choice, if the reasoning is correct, takes place in the conceptual component, whereas the profile choice belongs in the contextual component. Both components operate simulatenously, thus opting for more processing effort and high functional profile (and the associated low structural profile) or less processing effort and high structural profile (and the associated low functional profile). Afterwards, the relevant grammatical features are triggered and inserted into the grammatical expansion of the underlying predication. This is tantamount to saying that the processing effort choice is essentially cognitive: linear processing is cognitively less costly and semantically iconic, whereas parallel processing is cognitively more costly and 
semantically non-iconic. The impact of linear and parallel processing on syntax is not straightforward. Parallel processing is structurally marked, since discontinuous structures involve higher structural complexity than continuous structures; but it may be textually unmarked, given that continuous structures might be less frequent than discontinuous ones in some contexts, including, most probably, non-specific relativization in English intransitive clauses introducing a New Topic like:

(22) A woman came in whom I had met before somewhere

The conceptual component drastically restricts parallel processing. This may be stated by means of a functional principle like the following:

The Principle of Linear Processing

The conceptual component restricts parallel processing.

This principle stipulates that the restriction on parallel processing is cognitive, not grammatical. Syntactically speaking, nothing prevents expressions from containing more than one instance of discontinuous constituency. For the cognitive reasons given in this section, it seems plausible that the conceptual component limits the maximum of discontinuous constituency allowed per expression to two, one being the preferred option. In grammatical terms, discontinuous constituency distributes freely with any construction, except with itself.

\section{REFERENCES}

Bakker, D. 2001. "The FG Expression Rules: A Dynamic Model". Challenges and Developments in Functional Grammar (Revista Canaria de Estudios Ingleses 42). Ed. Pérez Quintero, M. J. La Laguna: Servicio de Publicaciones de la Universidad de La Laguna. 15-54.

Bakker, D., and A. Siewierska. 2002. "Adpositions, the lexicon and expression rules". New Perspectives on Argument Structure in Functional Grammar. Eds. Mairal Usón, R., and M. J. Pérez Quintero. Berlin: Mouton de Gruyter. 125-177.

Butler, C. 2003a. Structure and Function: A Guide to Three Major Structural-Functional Linguistic Theories, Part 1: Approaches to the Simplex Clause. Amsterdam and Philadelphia: John Benjamins.

- 2003b. Structure and Function: A Guide to Three Major Structural-Functional Linguistic Theories, Part 2: From Clause to Discourse and Beyond. Amsterdam and Philadelphia: John Benjamins. 
Connolly, J. 1991. Constituent Order in Functional Grammar: Synchronic and Diachronic Perspectives. Berlin: Foris.

Dik, S. C. 1980. Studies in Functional Grammar. London: Academic Press.

—. 1986. "On the notion 'functional explanation'”. Belgian Journal of Linguistics 1: $11-51$.

- 1997a. The Theory of Functional Grammar. Part 1: The Structure of the Clause. Ed. Hengeveld, K. Berlin: Mouton de Gruyter.

- 1997b. The Theory of Functional Grammar. Part II: Complex and Derived Constructions. Ed. Hengeveld, K. Berlin: Mouton de Gruyter.

Fischer, O., A. van Kemenade, W. Koopman, and W. van der Wurff. 2000. The Syntax of Early English. Cambridge: Cambridge University Press.

Givón, T. 1993. English Grammar. A Function-Based Introduction. Amsterdam: John Benjamins.

Hengeveld, K. 2004a. "The architecture of a Functional Discourse Grammar". $A$ new arquitecture for Functional Grammar. Eds. Gómez González, M. A., and J. L. Mackenzie. Berlin: Mouton de Gruyter. 1-21.

—. 2004b. "Epilogue". A new arquitecture for Functional Grammar. Eds. Gómez González, M. A., and J. L. Mackenzie. Berlin: Mouton de Gruyter. 365-378.

Kroch, A. 1989. "Reflexes of Grammar in Patterns of Language Change". Language Variation and Change 1: 199-244.

Levelt, W. 1989. Speaking: From Intention to Articulation. Cambridge, Mass.: MIT Press.

Mackenzie, J. L. 2001. "Adverbs and Adpositions: The Cinderella Categories of Functional Grammar". Challenges and Developments in Functional Grammar (Revista Canaria de Estudios Ingleses 42). Ed. Pérez Quintero, M. J. La Laguna: Servicio de Publicaciones de la Universidad de La Laguna. 119-136.

Martín Arista, J. 2001a. "Sintaxis medieval I: complementación, caso y sintaxis verbal”. Lingüistica histórica inglesa. Eds. de la Cruz Cabanillas, I., and J. Martín Arista. Barcelona: Ariel. 224-312.

—. 2001b. "Sintaxis medieval II: funciones, construcciones y orden de constituyentes”. Lingüística histórica inglesa. Eds. de la Cruz Cabanillas, I., and J. Martín Arista. Barcelona: Ariel. 313-377.

McCawley, J. D. 1998. The Syntactic Phenomena of English. Chicago: The University of Chicago Press.

Mitchell, B. 1985. Old English Syntax (2 vols.). Oxford: Oxford University Press.

Pintzuk, S. 1999. Phrase Structures in Competition. Variation and Change in Old English Word Order. New York: Garland Publishing. 
Quirk, R., S. Greenbaum, G. Leech, and J. Svartvik. 1991. A Grammar of Contemporary English. London: Longman.

Rijkhoff, J. 1986. "Word Order Universals Revisited. The Principle of Head Proximity". Belgian Journal of Linguistics 1: 95-125.

Van Valin, R. 1990. "Layered Syntax in Role and Reference Grammar". Layers and Levels of Representation in Language Theory. Eds. Nuyts, J., M. Bolkestein, and C. Vet. Amsterdam and Philadelphia: John Benjamins. 193-231.

Van Valin, R., and R. LaPolla. 1997. Syntax: Structure, Meaning, and Function. Cambridge: Cambridge University Press.

Visser, F. Th. 1963-1973. An Historical Syntax of the English Language (4 vols.). Leiden: Brill. 